\title{
AGRICULTURA FAMILIAR, IDENTIDADE SOCIAL E ARRENDAMENTOS RURAIS: A DIMENSÃO DO "HABITUS" NO ACESSO CONTRATUAL À TERRA.
}

\section{Luís Felipe Perdigão de Castro ${ }^{1}$}

Resumo: O presente artigo debate sociologicamente "quem são" os agricultores familiares e "quais fatores influenciam" a decisão sobre acessar terras, através de contratos agrários. Inicia-se com um breve panorama conceitual de agricultura familiar na América Latina, visitando definições técnicas regionais, para entender uma relativa convergência de significado sociocultural. Na sequência, são descritos elementos econômicos e sociais que condicionam de forma mais genérica os contratos agrários. $\mathrm{O}$ objetivo geral é, através de pesquisa bibliográfica e à luz da interpretação sociológica do Direito, estudar as formas de agir e viver da categoria social e suas interações contratuais, na perspectiva do "habitus" (Bourdieu, 2008b).

Palavras-chave: agricultura familiar; conceitos; acesso contratual à terra; habitus.

\section{THE FAMILY FARMING, SOCIAL IDENTITY AND TENANCIES: THE DIMENSION OF "HABITUS" IN CONTRACTUAL ACCESS TO LAND.}

\begin{abstract}
The present article discusses "who are" the family farmers and "what factors influence" the decision on accessing land, through agrarian contracts. It begins with a brief conceptual panorama of family farming in Latin America, visiting regional technical definitions, to understand a relative convergence of socio-cultural meaning. In the sequence, economic and social elements are described that condition agrarian contracts more generally. The general objective is, through bibliographical research and in light of the sociological interpretation of Law, to study the ways of acting and living of the social category and their contractual interactions, from the perspective of "habitus" (Bourdieu, 2008b).
\end{abstract}

Keywords: Family Farming; concepts; contractual acess to land; habitus.

\section{INTRODUÇÃO}

O acesso à terra rural é um direito humano, necessário à realização plena de uma série de outros direitos. Essa dimensão jurídica nos conduz a entender melhor o papel social e cultural da terra para a Agricultura Familiar no Brasil e na América Latina, ao tempo em que essa categoria social está, historicamente, ligada às lutas por terras, territórios e dignidade no meio rural (CASTRO, 2015a, p. 93; 2016). Mas, essa percepção não é suficiente por si só, deixando margens a perguntas como: o que

\footnotetext{
${ }^{1}$ Doutorando em Ciências Sociais, pela Universidade de Brasília (DELA/UnB). Mestre em Agronegócios (UnB), graduado em Direito (UFOP). Integra os grupos de pesquisa: Estudos Comparados de Sociologia Econômica; BICAS; LEIJUS e, ainda, o Grupo de Estudos Comparados México, Caribe, América Central e Brasil (MeCACB), vinculados à Universidade de Brasília (UnB). Coordena o grupo Terras e Territórios na América Latina: interfaces conceituais entre Direito e Ciências Sociais (Unidesc). Professor de graduação e pós-graduação da Faciplac e Unidesc.
} 
identifica aquele setor enquanto categoria social? Quem são os agricultores familiares? Sob quais aspectos técnicos se definem? São perguntas que, por um lado, motivam o presente artigo e, por outro, dão sentido a opções metodológicas. Nessa linha de indagações se inserem as categorias sociais e os contratos agrários ${ }^{2}$, mais especificamente, a agricultura familiar.

Sendo assim, o presente artigo descreve um percurso metodológico aplicado ao problema de pesquisa ${ }^{3}$, que consiste em descrever "quem são" os agricultores familiares e "quais fatores influenciam" sua decisão sobre acessar terras, através de arrendamentos rurais. O estudo baseia-se em um grupo representativo, localizado em Rio Verde/GO.

Nesse contexto, o presente trabalho se inicia expondo um breve panorama conceitual de agricultura familiar na América Latina, visitando definições técnicas regionais, para entender uma relativa convergência de seu significado sociocultural. Na sequência, são descritos elementos econômicos e sociais que condicionam de forma mais genérica os contratos agrários. O objetivo geral é, através de pesquisa bibliográfica e à luz da interpretação sociológica do Direito, estudar as formas de agir e viver da categoria social e suas interações com as configurações jurídico-contratuais, na perspectiva daquilo que Bourdieu (2008b) chamou de "habitus".

\section{AGRICULTURA FAMILIAR E DIVERSIDADE LATINO-AMERICANA}

A agricultura familiar é um elemento de complexidade latino-americana. Nesse sentido, "a cultura e a heterogeneidade socioeconômica que caracterizam o setor da agricultura familiar entre os países da América Latina e Caribe se replicam no interior de cada um deles" (SALCEDO; GUZMAN, 2014, p. 19) e, dessa forma, abordá-la é

\footnotetext{
2 Das modalidades de acesso à terra admitidas no Brasil, os arrendamentos rurais são os menos utilizados, ficando atrás da propriedade (direito real), da ocupação (direito de posse direta) e da parceria (direito contratual de uso temporário). Considerando o rol de formas de acesso, a literatura de juristas agraristas, economistas e sociólogos sustentam teses de que os arrendamentos rurais seriam contratos que melhoram o acesso à terra pelos mais pobres. Porém, o que instiga é que os dados censitários apontam baixos índices de arrendamento no Brasil (IBGE, 2007). Portanto, existe uma peculiaridade no caso brasileiro que consiste em termos alta concentração fundiária, com grande número de trabalhadores com pouca ou nenhuma terra e, mesmo assim, os arrendamentos não serem uma via alternativa para o acesso à terra (CASTRO, 2013; 2017).

${ }^{3}$ Este trabalho baseia-se em pesquisa de mestrado, desenvolvida no Programa de Pós-Graduação em Agronegócios (PROPAGA) da Universidade de Brasília (UnB), sob orientação do Prof. Dr. Sérgio Sauer e financiamento do Conselho Nacional de Desenvolvimento Científico e Tecnológico - CNPq. O tema desafia novos estudos e uma compreensão comparada sobre a prática contratual na América Latina. Guarda interface com as relações entre terra, territórios e identidades sociais, sendo tal questão problematizada atualmente, como tese de doutoramento do autor, sob orientação da Profa. Dra. Rebecca Lemos Igreja, no Departamento de Estudos Latino-Americanos, da Universidade de Brasília.
} 
conhecer as lutas por terra, poder, capital e direitos, que dizem respeito à definição mais ampla das próprias realidades latino-americanas. Dentre os desafios de se conceber o que seja a "América Latina" inclui-se a temática da "agricultura familiar latinoamericana", que desafia uma definição comum entre os países da região. Mais que isso, a categoria representa um traço marcante de diversidade, contradições e potencialidades (realizadas e latentes) da América Latina, em sua perspectiva rural (CASTRO, 2016, p. 78).

Um dos conceitos mais difundidos (e antigos) de agricultura familiar remonta aos Estados Unidos. A ideia de Family Farming, originada no século XX naquele país, definiu uma vertente de estudos sobre agricultura familiar, focando na predominância da mão-de-obra da família na produção e na vida rural norte-americana. Contudo, a concepção de Family Farming norte-americana não basta para compreender a complexidade da agricultura familiar latino-americana. Na América Latina, a ideia de agricultura familiar encontrou não somente uma prática, como também conceituações específicas à sua realidade. Tais definições começaram a ser formadas no fim do século XIX e início do século XX, influenciadas por estudos sobre paysannerie ou campesinato (CASTRO, 2016, pp. 78/79).

Uma das definições técnicas mais antigas sobre agricultura familiar latinoamericana vem de meados do século XX. Trata-se do termo "unidad economica familiar" (unidade econômica familiar), cujo sentido normativo coincide, em grande parte, com o de "módulo fiscal", adotado pelo Instituto Nacional de Colonização e Reforma Agrária do Brasil (INCRA). Sua significação, dentre outras denominações, foi utilizada por quase todos os países latino americanos em projetos de reforma agrária, assumindo finalidades analíticas e políticas (MALETTA, 2011, p. 08; SCHNEIDER, 2014; CASTRO, 2013; 2016, p. 82).

A unidade econômica familiar é uma gleba de tamanho suficiente para prover o sustento de uma família. Seu funcionamento requer a mão-de-obra estritamente familiar e não contratada. (CASTRO, 2016, p. 82). A partir desse conceito, a definição de

\footnotetext{
${ }^{4} \mathrm{O}$ módulo fiscal, no Brasil, corresponde à área mínima necessária a uma propriedade rural para que sua exploração seja economicamente viável. O tamanho do módulo fiscal para cada município brasileiro está fixado através de Instruções Especiais (IE) expedidas pelo INCRA, de acordo com a Lei no 8.629/93. O módulo fiscal também é parâmetro para a classificação fundiária do imóvel rural, sendo minifúndio o imóvel rural de área inferior a 1 (um) módulo fiscal; pequena propriedade o imóvel rural entre 1 (um) e 4 (quatro) módulos fiscais; média propriedade aquele de área entre 4 (quatro) e 15 (quinze) módulos fiscais e grande propriedade aquela superior a 15 (quinze) módulos fiscais. (CASTRO, 2016, p. 82).
} 
agricultura familiar foi historicamente identificada com a ideia de "uma terra trabalhada pela família, associando a contratação de trabalhadores assalariados com a exploração capitalista” (MALETTA, 2011, p. 08). Assim, grosso modo, embora as organizações não-governamentais (ONG's), universidades e organismos de cooperação adotassem o termo "agricultura familiar", somente a partir dos anos 2000, o conceito e seu uso foram popularizados nos meios políticos, acadêmicos e movimentos sociais da América Latina (DE LA O e GARNER, 2012).

Nessa trajetória, o termo e as discussões sobre agricultura familiar na América Latina permaneceram como herdeiras das "reflexões sobre o campesinato, durante a década de 1970 e sobre a produção de pequena escala durante os anos 1990" (SCHNEIDER, 2014, p. 07/08). Posteriormente, no início do século XXI um relativo consenso foi se formando entre estudiosos e formuladores de políticas públicas na América Latina, através da percepção de que as unidades familiares "não são necessariamente nem pobres, nem pequenas, nem muito menos desconectadas dos mercados, das cidades e da dinâmica social mais geral”. Somente em 2004, a expressão "agricultura familiar" foi pela primeira vez reconhecida oficialmente na América Latina, através da Reunião Especializada de Agricultura Familiar (REAF) do MERCOSUL (CASTRO, 2016, p. 81).

Contudo, a importância de se discutir a agricultura familiar não diz respeito apenas ao consenso possível sobre o termo definidor, nem se restringe à garantia de segurança alimentar ${ }^{5}$. Liga-se também a novas formas de se propor o desenvolvimento, na medida em que a categoria social evidencia formas de viver e agir peculiares, isto é, apresenta uma interação própria entre família, produção agrícola e meio ambiente (SAUER, 2003; 2008).

O termo agricultura familiar, neste trabalho, recupera o pensamento de Wanderley (1999, 2009a, 2009b), para quem a conceituação assume ares de novidade,

\footnotetext{
${ }^{5}$ Embora as atuais Constituições latino-americanas, a exemplo da do Brasil $(\mathrm{CF} / 88)$, não tenham dado à agricultura familiar um tratamento específico no tocante ao acesso à terra, esse direito está profundamente relacionado à existência e formas de reprodução social da categoria. Nesse sentido, a agricultura familiar é o principal ator social para a garantia do direito humano à alimentação adequada, este previsto (desde 2010) na Constituição Federal brasileira. Os agricultores familiares produzem cerca de $70 \%$ dos alimentos que são consumidos no planeta. No Brasil, esse segmento produz $87 \%$ da mandioca, $70 \%$ do feijão, $46 \%$ do milho, $38 \%$ do café, $34 \%$ do arroz, $21 \%$ do trigo, $60 \%$ do leite, $59 \%$ do rebanho suíno, $50 \%$ das aves e $30 \%$ dos bovinos. Toda essa capacidade produtiva ocorre em meio a uma realidade social em que os agricultores possuem pouca ou nenhuma terra (IBGE, 2007; FRANÇA et al, 2009; CASTRO, 2013; CASTRO, 2015b, p.04)
} 
designando conceitos já enraizados na sociedade brasileira como o tradicional camponês, agricultor de subsistência e pequeno produtor rural e incorpora, conceitualmente, os desafios da modernidade. A agricultura familiar, que se reproduz nas sociedades modernas, deve adaptar-se a um contexto socioeconômico próprio dessas sociedades, as quais levam a modificações importantes nas formas de vida social tradicionais (WANDERLEY, 1999, 2009a, 2009b; CASTRO e SAUER, 2012; CASTRO, 2015b, p. 04).

Partindo desses aspectos sociológicos, a agricultura familiar brasileira pode ser caracterizada a partir dos seguintes elementos: a) a gestão da unidade produtiva e os investimentos nela realizados são feitos por indivíduos que mantém entre si laços de sangue ou casamento; b) a maior parte do trabalho é igualmente fornecida pelos membros da família; c) a propriedade dos meios de produção (embora nem sempre da terra) pertence à família e é em seu interior que se realiza sua transmissão em caso de falecimento ou aposentadoria dos responsáveis pela unidade produtiva" (INCRA/FAO, 1996, p. 04). Tais aspectos possuem definição legal, com um viés mais operacional, através da Lei 11.326, de 24 de julho de 2006, que definiu o agricultor familiar no Brasil como aquele que pratica atividades no meio rural, atendendo, simultaneamente, aos seguintes requisitos: I - não detenha, a qualquer título, área maior do que 4 (quatro) módulos fiscais; II - utilize predominantemente mão-de-obra da própria família nas atividades econômicas do seu estabelecimento ou empreendimento; III - tenha renda familiar predominantemente originada de atividades econômicas vinculadas ao próprio estabelecimento ou empreendimento; IV - dirija seu estabelecimento ou empreendimento com sua família (BRASIL, 2006).

Embora essas definições pareçam bem delimitadas, o termo agricultura familiar se consolida e se difunde nos diferentes setores da sociedade e dos países latinoamericanos, como um guarda-chuva conceitual, que abriga grande número de situações, em contraposição à agricultura patronal, tendo como ponto focal da polarização o tipo de mão-de-obra e de gestão empregadas (NEVES, 1995). Tanto assim que, no cenário latino-americano, existem diferentes termos e marcos legais. Vejamos alguns:

Quadro 1: Denominação e critérios para a agricultura familiar em alguns países latino-americanos

\begin{tabular}{|c|c|c|c|c|c|c|}
\hline PAÍSES & DENOMINAÇÃO & $\begin{array}{c}\text { SUPERFÍCIE } \\
\text { E CAPITAL }\end{array}$ & TRABALHO & $\begin{array}{c}\text { GESTÃO } \\
\text { OU } \\
\text { ATIVIDADE }\end{array}$ & RENDA & $\begin{array}{c}\text { RESIDÊE } \\
\text { NCIA }\end{array}$ \\
\hline
\end{tabular}


Luís Felipe Perdigão de Castro

\begin{tabular}{|c|c|c|c|c|c|c|}
\hline ARGENTINA & $\begin{array}{l}\text { Pequeño produtor } \\
\text { agropecuario }\end{array}$ & $\begin{array}{l}\text { Limite por } \\
\text { região }\end{array}$ & $\begin{array}{l}\text { Sem } \\
\text { assalariado } \\
\text { permanente }\end{array}$ & $\begin{array}{l}\text { Trabalho } \\
\text { direto sobre a } \\
\text { terra }\end{array}$ & $\begin{array}{l}\text { Sem } \\
\text { limite }\end{array}$ & $\begin{array}{l}\text { Sem } \\
\text { critério }\end{array}$ \\
\hline BRASIL & Agricultor Familiar & $\begin{array}{l}\text { Até } 4 \text { módulos } \\
\text { fiscais }\end{array}$ & $\begin{array}{l}\text { Até } 01 \text { ou } 02 \\
\text { assalariados } \\
\text { permanentes }\end{array}$ & $\begin{array}{l}\text { Gestão } \\
\text { familiar }\end{array}$ & $\begin{array}{l}70 \% \text { de } \\
\text { renda } \\
\text { familiar } \\
\text { da terra }\end{array}$ & $\begin{array}{l}\text { Residir na } \\
\text { terra }\end{array}$ \\
\hline CHILE & $\begin{array}{l}\text { Agricultor familiar } \\
\text { campesino }\end{array}$ & $\begin{array}{l}\text { Até } \\
\text { hectares de } \\
\text { irrigação } \\
\text { básica e ativos } \\
\text { menores que } \\
96 \text { mil USD }\end{array}$ & $\begin{array}{l}\text { Trabalho de } \\
\text { familiares } \\
\text { diretamente } \\
\text { sobre a terra }\end{array}$ & $\begin{array}{l}\text { Trabalho } \\
\text { direto sobre a } \\
\text { terra }\end{array}$ & $\begin{array}{l}\text { Renda } \\
\text { principal } \\
\text { ser } \\
\text { familiar } \\
\text { na } \\
\text { unidade }\end{array}$ & $\begin{array}{l}\text { Sem } \\
\text { critério }\end{array}$ \\
\hline COLÔMBIA & $\begin{array}{l}\text { Unidad Agricola } \\
\text { Familiar (UAF) }\end{array}$ & $\begin{array}{l}\text { UAF com } \\
\text { patrimônio } \\
\text { familiar }\end{array}$ & $\begin{array}{l}\text { Trabalho de } \\
\text { familiares, } \\
\text { com } \\
\text { possibilidade } \\
\text { de } \\
\text { assalariados }\end{array}$ & $\begin{array}{l}\text { Trabalho } \\
\text { baseado na } \\
\text { atividade } \\
\text { agropecuária, } \\
\text { aquícola e } \\
\text { florestal }\end{array}$ & $\begin{array}{l}\text { Sem } \\
\text { limite }\end{array}$ & $\begin{array}{l}\text { Sem } \\
\text { critério }\end{array}$ \\
\hline PARAGUAI & $\begin{array}{l}\text { Agricultura } \\
\text { Familiar } \\
\text { Camponesa }\end{array}$ & $\begin{array}{l}\text { Sem nenhum } \\
\text { limite }\end{array}$ & $\begin{array}{l}\text { Trabalho de } \\
\text { familiares } \\
\text { diretamente } \\
\text { sobre a terra, } \\
\text { podendo ser } \\
\text { contratados } \\
\text { até } 20 \\
\text { assalariados }\end{array}$ & $\begin{array}{l}\text { Gestão pela } \\
\text { família }\end{array}$ & $\begin{array}{l}\text { Sem } \\
\text { limite }\end{array}$ & $\begin{array}{l}\text { Residir na } \\
\text { unidade } \\
\text { familiar } \\
\text { ou em } \\
\text { suas } \\
\text { cercanias }\end{array}$ \\
\hline URUGUAI & Productor Familiar & $\begin{array}{ll}\begin{array}{l}\text { Até } \\
\text { hectares }\end{array} & 500 \\
\text { (índice } & 100 \\
\text { Coneat } & \\
\text { urugruaio) } & \end{array}$ & $\begin{array}{l}\text { Trabalho de } \\
\text { familiares } \\
\text { sobre a terra, } \\
\text { podendo } \\
\text { haver até } 02 \\
\text { salários } \\
\text { permanentes } \\
\text { ou } 500 \\
\text { jornadas/ano }\end{array}$ & $\begin{array}{ll}\text { Gestão } & \\
\text { Familiar } & \text { "o } \\
\text { jefe } & \text { de } \\
\text { família" } & \end{array}$ & $\begin{array}{l}\text { Renda e } \\
\text { trabalho } \\
\text { familiares } \\
\text { sobre a } \\
\text { terra }\end{array}$ & $\begin{array}{l}\text { Até } 50 \\
\text { quilômetr } \\
\text { os da } \\
\text { unidade } \\
\text { familiar }\end{array}$ \\
\hline
\end{tabular}

Fonte: CASTRO (2016, pp. 83/84), com base em SABOURIN, E., SAMPER, M., e SOTOMAYOR ECHENIQUE (2014, p. 28).

O quadro acima demonstra que o termo agricultura familiar se desdobra em diversas outras denominações, a exemplo da Argentina (Pequeño Productor Agropecuario), Brasil (Agricultor Familiar), Chile (Agricultor familiar campesino), Colômbia (Unidad Agrícola Familiar-UAF), Paraguai (Agricultura Familiar Campesina), Uruguai (Productor Familiar), bem como Agricultura Familiar Agroecológica Campesina (AFAC), na Comunidade Andina (CASTRO, 2016). Fica evidente a diversidade de termos e limites de definição técnica que permeiam a categoria social. Ao analisar tais nuances, a agricultura familiar latino-americana é, com todas as suas diferenças internas, um espaço social que "não significa uma ruptura total e definitiva com as formas anteriores, devendo o agricultor familiar adaptar-se as novas exigências da sociedade, sem desvincular-se das tradições camponesas" (WANDERLEY, 2009, p. 41/43). 
Por esse caminho, as concepções de mundo são produtos do sujeito, mas também um agregado de situações provenientes da categoria social, ao longo de um trajeto histórico. Essas relações podem ser interpretadas a partir da dinâmica de um "habitus" no espaço social. Segundo Bourdieu (2008, p. 162), o "habitus" é a “interiorização da exterioridade e a exteriorização da interioridade". Ou seja, um conjunto de disposições gerais e transponíveis - socialmente construídas e incorporadas - que fazem com que o conjunto de práticas seja produto de condições sociais semelhantes e, da mesma forma, sejam sistematicamente distintas de outras (CASTELLS, 2003; 2010; CATANI, 2002, p. 111).

Assim, o "habitus" baseia as distinções no espectro das práticas sociais. Permite compreender que o agricultor familiar age racionalmente, realizando práticas que reproduzem e transformam as estruturas sociais do espaço social em que se insere. A formação e o desenvolvimento da agricultura familiar segue a lógica de reprodução da vida social, envolvendo tanto a mudança de algumas estruturas quanto a permanência de outras (WANDERLEY, 1999). É um processo dinâmico, não implica na perpetuação imutável de uma realidade, mas se dá em meio a transformações e adaptações, marcadas pela produção e reprodução das condições de sobrevivência, através de estratégias (BOURDIEU, 1992, p. 114).

A estratégia é o resultado da articulação de um "habitus", que é essa espécie de senso prático do que se deve fazer em dada situação. Algumas das estratégias de reprodução da agricultura familiar, como a partilha da herança, a organização do trabalho familiar, a escolarização dos filhos (LAMARCHE, 1993) ou a pluriatividade (WANDERLEY, 1999; FERREIRA, 1995) estão diretamente relacionadas com o juízo de oportunidade e conveniência que o agricultor forma no momento de decidir se deve ou não arrendar. Outras estratégias, ligadas à matéria contratual, têm sido estudadas e mostram os esforços desses agricultores em se viabilizarem como tal, como a integração de produção junto a indústrias (PAULILO, 1990), formas de associativismo e cooperação (FERREIRA, 1995) ou a formação de contratos híbridos (CASTRO, 2013; 2017). Todas essas estratégias constituem respostas dos agricultores aos desafios gerados pelos bloqueios históricos.

Mesmo diante das diferenças terminológicas, a noção de agricultura familiar converge como "conceitos-síntese", isto é, "mais que simples categorias empíricas, à 
medida que teriam uma construção, apropriação e uso voltados para a expressão de identidades sociais" (SAUER, 2008, p. 67).

Não obstante, sua amplitude, há um sentido analítico e político. A agricultura familiar sob a perspectiva de uma "categoría social diversa y heterogénea" se consolidou pelo "papel estratégico en el proceso de desarrollo social y económico de los países de la región". Portanto, adquiriu "una centralidad política tanto para las organizaciones internacionales como para los movimientos sociales, los sindicatos y las cooperativas, al igual que para los partidos políticos y para los programas y las políticas públicos" (SCHNEIDER , 2014, p. 08). Assim, no âmago da diversidade, há, em comum, "uma racionalidade intrínseca ao agricultor familiar, que consiste em ultrapassar o pacto capital-terra, criando novas visões sobre o que seja desenvolvimento econômico, social e político" (CASTRO, 2013, p. 76).

\section{MATERIAL, MÉTODOS E RESULTADOS}

A pesquisa objetivou compreender as condicionantes do arrendamento rural na Agricultura Familiar. Com esse intuito, foram realizadas entrevistas em profundidade com vinte pessoas de Rio Verde/GO. Como método para coleta, o levantamento de informações ocorreu através da realização de entrevistas em profundidade. Esse recurso metodológico consiste em conversas face a face, permitindo que se explore e aprofunde a investigação, descrevendo processos e fluxos, com vistas a analisar, discutir e fazer prospectivas (MARCONI e LAKATOS, 2005) (CASTRO, 2013; 2017).

Assim, obtivemos o rol preliminar de entrevistados que, de forma mais ou menos aproximada, retrataram os perfis da agricultura familiar brasileira, conforme as tipagens de Baiardi (1999). Nesse modelo, são retratadas cinco diferenciações internas $(\mathrm{A}, \mathrm{B}, \mathrm{C}, \mathrm{D}, \mathrm{E})$, classificando os agricultores em diferentes extratos. O tipo A é aquele agricultor tecnificado, com forte inserção mercantil (predominante na região de cerrado, geralmente ligado à produção de grãos). O tipo B abarca os integrados verticalmente em Complexos Agroindustriais - aves e suínos, por exemplo - mais recentemente em perímetros irrigados voltados à produção de frutas. No tipo $\mathrm{C}$ encontra-se a agricultura familiar tipicamente colonial - presente no Rio Grande do Sul, Paraná, Santa Catarina e Minas Gerais - em que há policultura combinando lavouras, pomares com a pecuária e 
a criação de pequenos animais. O tipo $\mathrm{D}$ representa pessoas da agricultura familiar semimercantil - predominante no Nordeste e no Sudeste - e, por fim, o tipo E de origem semelhante ao tipo $\mathrm{D}$, porém caracterizado pela marginalização do processo econômico e pela falta de horizontes (CASTRO, 2013, p. 78).

Com base nesses perfis, foram selecionados 20 (vinte) agricultores, sendo 16 (dezesseis) agricultores familiares, dentre os quais 8 (oito) provenientes de áreas de assentamento de reforma agrária e 8 (oito) de propriedades particulares. Outros 4 (quatro) entrevistados eram provenientes da agricultura não 14 familiar, ligados a empreendimentos agroindustriais de Rio Verde. Realizaram-se entrevistas sobre uma amostra não probabilística (de conveniência), representativa do objeto pesquisado, com o intuito de captar as percepções dos agricultores familiares em relação ao arrendamento rural, utilizando as visões complementares de agricultores não familiares para enfatizar peculiaridades valorativas ${ }^{6}$.

Os dados obtidos permitiram a sistematização de três (3) subgrupos, constituídos pelos critérios de autodenominação, adequação ao conceito legaloperacional da Lei 11.326/06 e análise das relações internas de seus integrantes. Dessa forma foi possível sintetizar o perfil dos entrevistados para compreender o processo decisório segundo características elementares da categoria social (CASTRO, 2013, p. 96/99).

No subgrupo 1 identificamos pessoas que se definiram como "agricultores familiares". No subgrupo 2, os entrevistados se identificaram como "pequeno proprietário", "agricultor menor" ou mesmo "lavrador". Já as pessoas do terceiro subgrupo se autodefiniram como "empresário", "empresário rural", "empreendedor rural" ou ainda "arrendatário" ligado a grandes empreendimentos agroindustriais (CASTRO, 2013, p. 96/99). Todas as pessoas do subgrupo 1 se enquadraram perfeitamente na definição legal de agricultor familiar, enquanto nenhum integrante do subgrupo 3 pôde ser, do ponto de vista legal, considerado agricultor familiar. Ou seja, nesses casos, houve uma convergência entre autodenominação e enquadramento legal.

\footnotetext{
${ }^{6}$ Para obter tais informações, optamos por Rio Verde/GO, um município inserido no Sudoeste do Estado de Goiás, reconhecido por uma estrutura agroindustrial altamente organizada (FETAEG, 2002; IBGE 2007). Do ponto de vista do acesso às comunidades e aos perfis socioculturais, há presença de cooperativas agrícolas, com diferentes públicos (CASTRO, 2013; 2017)
} 
No subgrupo 2 constatamos uma peculiaridade: os agricultores não se autodenominaram "familiares", embora o fossem nos termos da Lei 11.326/06. Nesse subgrupo estão agricultores em grave descapitalização e outros que já deixaram suas terras. Os que ainda permanecem tendem a deixar de se enquadrar na acepção legal do termo, pois o trabalho externo (urbano) vem assumindo importância crescente na subsistência da família (CASTRO, 2013).

Tanto no subgrupo 1, quanto no 2, predomina a mão-de-obra familiar, contudo, em contextos muito distintos. No subgrupo 1, a mão-de-obra familiar tende a ser complementada por vizinhos e contratações eventuais, para incrementar e expandir a capacidade da unidade. Já no subgrupo 2 a dinâmica é inversa, pois ocorre uma progressiva saída de familiares da propriedade, fazendo com que a mobilização dos esforços laborais diminua e a unidade seja cada vez menos responsável pela subsistência e trabalho da família. Por sua vez, o subgrupo 3 apresenta uma organização empresarial do trabalho (contratações formais e celetistas).

Tal sistematização simplificou o perfil dos entrevistados e, ao mesmo tempo, ressaltou (pela diferenciação) algumas características elementares da agricultura familiar. As diferenças de linguagens, representações e valores evidenciaram vínculos mais profundos entre as pessoas de um mesmo subgrupo (espaço social), expondo formas de agir e viver que manifestam o significado da terra, a importância da família, as limitações legais para as atividades desenvolvidas, a transmissão de saberes, as relações de trabalho, etc.

A articulação desses elementos ocorre na dinâmica do "habitus", isto é, através de um diálogo constante entre realidades subjetivas e objetivas. Para tornar esse diálogo mais acessível à pesquisa, os dados foram organizados a partir de dimensões e lógicas, tidas como estruturas estruturantes do processo decisório sobre se tornar um arrendatário ou arrendador rural (CASTRO, 2013).

Por esse viés, para compreender melhor as condicionantes sobre o arrendamento rural, interpretamos os dados considerando que: a) as dimensões e lógicas seriam, no tocante ao arrendamento rural, os elementos específicos pelos quais se manifestam "uma manha", ou ainda, "uma infinidade de esquemas particulares diretamente aplicados a situações particulares" (BOURDIEU, 2009, pp. 208/209); b) 
particularmente, as dimensões são elementos característicos do espaço social do grupo de agricultores familiares entrevistados, em que predomina o domínio simbólico, gerador das possibilidades distintas mais elementares (CASTRO, 2013, p. 91); c) as lógicas, por sua vez, exprimem o diálogo mais imediato das pessoas com o meio, evidenciando operações práticas, no âmbito da decisão (CASTRO, 2013, p. 87). Partindo das percepções de ordem mais genérica e abstrata (dimensões teleológica, legal e sociocultural) é possível analisar operações práticas que dizem respeito à concretização do contrato e que decorrem dessas dimensões. As estruturas estruturantes, a que denominamos "lógicas" do agricultor familiar no contrato de arrendamento rural, se manifestam como elementos específicos e reflexivos, sobretudo de ordem prática. Manifestam-se como última fronteira de percepção antes da decisão sobre o contrato de arrendamento rural.

No rol das dimensões, a "dimensão teleológica" abarca as finalidades que o agricultor confere a certas coisas, dentre elas a terra. A terra não é somente um recurso produtivo, mas, antes de tudo, é lar, canto, cantinho, cuja missão é produzir para o bem de todos (família e comunidade). Entre os agricultores familiares assentados, a terra é fruto de luta e resistência, razão pela qual assume um significado político e cultural muito forte (conquista coletiva e realização de um sonho) (CASTRO, 2013, p. 115/118).

Para os agricultores familiares entrevistados, em geral, a terra é meio e fim, pois nela e por ela se realizam coisas da vida, como o trabalho, moradia e alimentação. Através dessas significações, o contrato de arrendamento rural foi visto, pela maior parte dos entrevistados, como um acordo eminentemente comercial. Para eles, dispor sobre a terra (através do arrendamento rural) não é simplesmente alugar terras, mas negociar aquilo que thes é central para organização e sobrevivência da família. As finalidades e significações atribuídas à terra tornam seu uso e fruição um bem da e para a família, que dificilmente é posto sob livre comercialização (CASTRO, 2013, p. $115 / 135)$.

$\mathrm{Na}$ "dimensão legal" se inserem elementos atinentes à percepção do Direito e desdobramentos de caráter extrajurídico. A vedação do arrendamento em certas áreas (assentamentos de reforma agrária) e a preocupação em mostrar que são pessoas honestas e honradas é uma valoração recorrente, que permeia a concepção de "cumprir a lei”. Nesse sentido, realizar o arrendamento rural nessas áreas é visto como algo errado, 
ruim e que compromete a honra da comunidade, pois coloca o agricultor na delicada situação de perder a posse da terra por ato ilícito. Ou seja, independente do teor do contrato e seus objetivos, menciona-se o argumento legal contra a prática (CASTRO, 2013, p. 118/121).

Por outro lado, a busca por legalidade também representa uma forma de externar o respeito à finalidade da terra, negando a pretensão de vender ou desviar seu uso, no caso de agricultores familiares assentados. Em relação aos agricultores familiares tradicionais, e mesmo para os assentados, a dimensão legal não se esgota na ideia de ser dono (direito real de propriedade). Não basta ser dono, é preciso estar em conformidade com o direito para ser reconhecido, respeitado e ter visibilidade perante a família e a sociedade. Por esse viés, o contrato de arrendamento é tido como um negócio arriscado, à medida que pode gerar dívidas, procedimentos e processos judiciais que abalam o patrimônio moral e afetivo que o agricultor sustenta do ponto de vista pessoal e formal-jurídico (CASTRO, 2013).

$\mathrm{Na}$ "dimensão sociocultural" predomina uma série de preocupações com a reprodução social da família. O foco dos agricultores familiares entrevistados é a reprodução de suas formas de agir e viver, o que inclui garantir a posse da terra. Nesse sentido, o arrendamento rural é visto como um contrato que, por ser limitado no tempo, não dá a posse definitiva da terra para que a família garanta o horizonte das gerações, com uma organização própria do tempo e do espaço.

A questão da posse repercute também sobre a autonomia que o agricultor necessita para gerir suas atividades. A seu ver, o arrendamento rural não dá liberdade suficiente para agir conforme as necessidades da família, afinal, existem cláusulas prédefinidas para uso, fruição e produção. Ou seja, os entrevistados (agricultores familiares) percebem o arrendamento rural como incompatível com o desejo de trabalhar para si, organizando o tempo e o espaço ao modo da família (CASTRO, 2013, p. 121/124).

As dimensões e lógicas presentes nas narrativas e discursos dos entrevistados organizam estruturas discursivas (dimensões e lógicas). As dimensões não são estáticas, pois não se fecham sobre seus próprios limites. Suas fronteiras não são intransponíveis, isto é, um elemento sob a perspectiva de uma dimensão apresenta nuances (diálogos) 
que avançam sobre as demais, como é o caso da mão-de-obra utilizada pelos entrevistados, que assume uma dimensão teleológica (terra como lugar de trabalho) e sociocultural (trabalho como atividade da família). Essas relações nos permitem compreender o caráter cumulativo das experiências e percepções da realidade.

A tradução das dimensões para a prática contratual ocorre sob o diálogo imediato entre a necessidade e a possibilidade do agricultor familiar, ou seja, mediante um encadeamento de lógicas sociais, econômicas, culturais e técnico-contratuais. Os dados subjetivos (como: arrendar de que forma, sob quais condições, para que, para quem e quanto) e objetivos (como: haver escassez de terras na localidade, alto custo de insumos na região, alta competitividade em Rio Verde) são postos diante de si e da decisão sobre o arrendamento rural, criando na prática a percepção sobre a conveniência e oportunidade das operações contratuais.

O processo decisório é, portanto, uma operação complexa e reflexiva. Existem implicações práticas para o contrato, através de lógicas que dizem respeito à operacionalização das avenças. ${ }^{7}$ Essa proximidade no espaço social não denota somente uma lógica social, mas viabiliza também a existência de contratos híbridos. Identificamos a criação de arrendamentos rurais com forte tendência à parceria (partilha de riscos e despesas), evidenciando uma lógica técnico-contratual peculiar ${ }^{8}$. Além disso, o quantitativo de mão-de-obra disponível na unidade é outro fator que incide sobre a decisão. Ou seja, os agricultores familiares entrevistados só decidem pelo arrendamento rural, ainda que híbrido, na medida em que os braços da família são suficientes para agregar novas áreas e o risco de endividamento está sob controle. Por outro lado, a resistência em deixar suas terras para se tornar arrendador evidenciou uma lógica cultural que compõe o processo decisório, sob a ótica das afetividades da família. A terra é, sobretudo, o lugar das afetividades, daquilo que "não tem preço".

Em suma, da combinação das "dimensões teleológica, legal e sociocultural”, o arrendamento rural se conforma por uma série de lógicas ligadas à prática, à vida

\footnotetext{
${ }^{7}$ Exemplo disso é o fato do contrato ser visto como um acordo a ser firmado entre parentes, amigos, conhecidos de culto religioso ou associações, para os quais a terra assume um significado especial e compartilhado. Os laços sociais entre os contratantes são decisivos, pois permitem que o contrato surja e se desenvolva em uma relação de iguais (baseada na "boa vizinhança").

${ }^{8}$ Trata-se da combinação de dois aspectos: a) o arrendamento rural apresenta a figura do arrendador, do arrendatário, da renda e da cessão do uso (arrendamentos verdadeiros) e; b) a execução contratual é permeada por benefícios e obrigações que extrapolam as partes contratantes, formando contratos em teia, com familiares e conhecidos.
} 
cotidiana e real dos agricultores familiares (lógica social, cultural, econômica, técnicocontratual, etc), que permitem uma série de interpretações sobre o processo decisório.

\section{DISCUSSÃO: PERCEPÇÕES E CONFIGURAÇÕES DA PRÁTICA}

Os materiais (narrativas e discursos) provenientes das entrevistas em profundida nos permitem avaliar que, diante do que a terra significa para o agricultor familiar, os contratos de arrendamento rural são vistos pelos entrevistados como instrumentos muito limitados para incluir cláusulas que conciliem a terra enquanto recurso produtivo, espaço geográfico e simbólico. É visto como um contrato de caráter fortemente comercial, arriscado (do ponto de vista legal e econômico) e de posse temporária, não sendo um mecanismo ou instrumento suficiente para garantir o acesso à terra como lugar de trabalho e de vida (CASTRO, 2013, p. 124/152).

A resistência é mais baixa com relação a se tornar arrendatário, pois os entrevistados viram nessa posição contratual uma menor chance de perdas, especialmente afetiva (deixar a terra). Alguns avençaram a possibilidade de acessar novas áreas para cultivos mais rentáveis como a soja e o sorgo. Esses entrevistados manifestaram o desejo de serem arrendatários de terras próximas às suas, de pessoas conhecidas e em pequenas dimensões (até 15 hectares). Contudo, alegaram que arrendar terras de agricultores não familiares é uma possibilidade muito remota em Rio Verde, pois a maior parte dos proprietários procura firmar contratos formais, com adiantamentos de renda e garantias reais, que não estão condizentes com a realidade dos agricultores familiares entrevistados.

Nesse discurso, o ambiente altamente seletivo e competitivo tem caráter excludente, reforçado pela representação de que o arrendamento é um contrato típico dos grandes empreendimentos agrário-capitalistas. Há uma desconstrução do arrendamento rural, no âmbito da percepção, como alternativa de acesso à terra e o termo "arrendatário" passa a ser sinônimo de "empresário rural". Essas repercussões contratuais permitem compreender quando o processo decisório do agricultor familiar se aproxima ou se distancia da conclusão de um contrato de arrendamento rural.

Dessa forma, os fatores condicionantes do arrendamento podem ser postos considerando quatro situações (padrões derivados da legislação vigente): "Configuração 
1": Agricultor Familiar (Arrendatário) contrata com Agricultor Familiar (Arrendador); "Configuração 2": Agricultor Familiar (Arrendador) contrata com Agricultor Familiar (Arrendatário); "Configuração 3": Agricultor Familiar (Arrendatário) contrata com Outra categoria social (Arrendador); "Configuração 4":Agricultor Familiar (Arrendador) contrata com Outra categoria social (Arrendatário).

Dentre as hipóteses de relações contratuais acima, o agricultor familiar pode ser arrendatário de terras, no contexto em que contrata com outro agricultor familiar (parte arrendadora). Nessa situação, as percepções sobre os fatores determinantes para o arrendamento rural foram os seguintes:

a) Haver mão-de-obra disponível na família do arrendatário, para cultivar novas terras; b) Haver vínculos afetivos e sociais entre arrendante e arrendatário, especialmente com parentesco familiar, visando relações de confiança para que o contrato contenha menor formalidade (oralidade ou registro cartorial simples), além de equalizar o poder de barganha (relações entre iguais, sem cunho meramente comercial, para fixar a renda). É muito comum que a casa de um dos agricultores, a sede da cooperativa ou o templo religioso sejam ambientes nos quais os contratos são solenizados; c) Haver proximidade física das glebas a serem arrendadas, dando a perfeita noção de que há continuidade entre as áreas; d) Haver similaridade nas características naturais da área arrendada (solo, vegetação, recursos hídricos, inclinação do terreno) diminuindo a possibilidade do fator surpresa com pragas, correções de solo e irrigação. Essa similaridade leva em conta também a composição da paisagem, incluindo a noção estética, contemplativa, e mesmo bucólica, do ambiente rural como um espaço de relativa harmonia com a natureza; e) Haver possibilidade dos cultivos da área originária serem levados às áreas arrendadas, com aproveitamento de mão-de-obra e experiência da família; f) Haver experiência anterior com a prática contratual, especialmente no histórico familiar (pais e avós) ou de amigos próximos, que tornem a prática mais referenciada para a família. Essa partilha de informações e experiências acaba levando muitos arrendamentos a uma grande diversidade de regras formais e informais (divisão de trabalho e produtos, empréstimo condicional de máquinas, modificação de cultivo, alteração superveniente de prazos para além das previsões legais, disposição de benfeitorias) que geram formas híbridas (CASTRO, 2013, p. 124/152). 
Porém, como as relações contratuais são dinâmicas, o agricultor familiar pode ser arrendatário de terras, no contexto em que a parte arrendadora seja um agricultor patronal ou empreendimento empresarial. Nessa situação, as percepções mudam, pois o contrato de arrendamento com agricultores patronais ou empresários agrícolas (categorias sociais diferentes) tem por pano de fundo as diferenças sociais e de recursos entre arrendador e arrendatário. Isso reforça a importância das similitudes (econômicas e culturais, como vimos no tópico acima) para os arrendamentos rurais entre agricultores familiares.

A maior parte dos agricultores familiares oferece garantias contratuais imateriais (reputação pública e ligações familiares) ou, quando muito, pequenos imóveis/máquinas que não sejam essenciais à sobrevivência da família. Os entrevistados do subgrupo 1 (agricultores familiares) e do subgrupo 3 (categoria social não familiar) são unânimes em relatar que os agricultores familiares não podem oferecer a segurança contratual exigida nos contratos firmados com agricultores patronais, não só pela limitação de seus recursos, mas pela alta competitividade local.

A existência de empreendedores rurais interessados em arrendar, oferecendo fortes garantias reais (imóveis, terras, direitos) e operacionais (experiência com porte institucional e infraestrutura especializada), reafirma o aspecto discursivo já citado, de que os agricultores familiares entrevistados percebem os arrendamentos rurais em Rio Verde como "contratos para agricultores ricos". À medida que se torna uma prática cada vez mais concentrada em categorias sociais detentoras de capital, terra e informação, os agricultores familiares apresentam uma baixa expectativa sobre a concretização desses contratos com outras categorias sociais.

Por outro lado, devem-se considerar também fatores determinantes na situação em que o agricultor familiar (como arrendador de terras) contrata com outro agricultor familiar, este na condição de parte arrendatária. Nesse caso, os vínculos afetivos e sociais entre arrendante e arrendatário continuam importantes. Embora as garantias reais (imóveis, máquinas e direitos) sejam significativas, é a reputação pública (senso de honradez) do agricultor na comunidade que deflagra todo o processo de negociação ou de negativa do arrendamento. 
As histórias de família, a tradição no local, o tempo de moradia, o cumprimento de contratos anteriores e as consultas cartoriais simples são meios para captação de informações sobre a viabilidade do contrato. A proximidade física das glebas também interfere, pois permite a fiscalização do uso das terras, bem como das relações de compadrio que, naturalmente, são mais fortalecidas (trazendo formas adicionais de colaboração, através de empréstimo de máquinas, planejamento de cultivos, acesso a transporte, compras conjuntas, etc.). Por extensão, a identidade ou similaridade na gestão da propriedade é um fator determinante, pois diminui o desgaste dos recursos produtivos e preserva a paisagem anterior (o que inclui combinados sobre a preservação de tal árvore centenária, não desfazer determinado pomar, evitar que o gado atravesse o curso de água, etc.).

Dentre os polos contratuais possíveis, é possível o agricultor familiar como um arrendador de terras, no contexto em que a parte arrendatária seja um agricultor patronal ou empreendimento empresarial. Nessa configuração, de acordo com os dados de campo, os elementos discursivos mudam profundamente. Os agricultores mais descapitalizados (subgrupo 2) identificaram o arrendamento rural como uma forma positiva de se capitalizarem, bem como de sobreviverem através da renda, obtendo recursos para moradia, alimentação, saúde, sem o ônus do trabalho no meio rural. Nesse sentido, sua intenção é a cessão da terra através de contrato formal, que garanta basicamente o retorno da propriedade e o valor da renda em dinheiro. A lógica subjacente é a de obter o pagamento de renda, superior à receita ou à subsistência gerada pela propriedade.

Por outro lado, os demais agricultores familiares (aqueles que produzem o suficiente para subsistência e/ou para comercializar excedentes) manifestaram resistência a arrendar suas terras para um arrendador da agricultura patronal ou empreendimento empresarial. Nesse sentido, diversos fatores desestimulariam esses tipos de arrendamentos. O primeiro seria o temor de perder a terra para o arrendatário patronal ou empresarial, por razões ligadas às diferenças de poder econômico e político entre as partes. O agricultor familiar avalia sua inferioridade de recursos (econômicos, políticos e de informação) como um fator de risco, que pode ensejar menor poder de barganha sobre a renda, pressão para venda e apossamento das terras. Na prática, não há confiança no lado mais empoderado da relação, que poderia agir pela via da violência 
direta (remoção de cerca, coação armada, etc.), mas principalmente por manobras institucionais e legais (ações judiciais, força policial, mecanismos políticos, etc.).

Nas entrevistas realizadas fica muito claro que a concentração dos arrendamentos nas categorias sociais tidas como "empresários agrícolas" tem por pano de fundo a desigual distribuição de recursos no campo, mantendo-se como um contrato adequado ao modelo agroexportador, monocultor e que, como os próprios entrevistados observaram, tende a se tornar arrendatário de vastas áreas. Isto é, o arrendamento formal e estável restringe-se a categorias sociais que já possuem capital, tecnologia e informação e, por isso, acessam cada vez mais terras por via contratual (CASTRO, 2013).

Os resultados vão no sentido de que a agricultura familiar representa, não somente uma categoria social, mas também uma categoria de sujeitos políticos que constrói visões de mundo próprias, acerca da terra e das formas de produzir bens e serviços. Por conseguinte, é diversa, ampla e extensa. Existe na América Latina, de um país para outro e dentro dos próprios países, sob uma diversidade de situações históricas, sociais e técnico-produtivas de múltiplos segmentos de produtores agropecuários, transmudando-se ora em "agricultura campesina", "pequeña agricultura" ou "producción a pequeña escala" (MARQUES e RAMOS, 2012; PIADAL, 2013).

Assim, como um "guarda-chuva conceitual", o termo agricultura familiar na América Latina abriga "grande número de situações, em contraposição à agricultura patronal, tendo como ponto focal da polarização os tipos de mão-de-obra e de gestão", os quais são essencialmente familiares. As unidades de produção familiar seriam "formas de conexão, de disjunção e de conjunção", sistemas de "procedimentos e de estratégias e não uma estrutura dada, a qual aos indivíduos só cabe a própria modelação (NEVES, 1995, p. 34).

\section{CONSIDERAÇÕES FINAIS}

A agricultura familiar latino-americana representa não somente uma categoria social, mas também um conjunto heterogêneo de sujeitos políticos, que constroem visões de mundo próprias, acerca da terra e das formas de produzir bens e serviços (CASTRO, 2015, p. 96). 
A partir disso, a dinâmica do "Habitus" foi interpretada segundo dimensões e lógicas do processo decisório, confirmando a hipótese de que a opção sobre arrendar ou não as terras é mais que uma opção jurídica ou econômica, devendo ser tratada como parte de um processo social de múltiplas dimensões. Nesse sentido, a desigual distribuição de capital, informação e terras, em última instância, impede que o arrendamento se torne uma prática contratual democrática, acessível e equilibrada. Nos relatos dos entrevistados, percebe-se que o arrendamento rural não é praticado entre categorias diferentes, por ser visto com descrença ou temor, pois, muitos acordos, sob a pressão de imperativos econômicos, não atendem ao significado teleológico, legal e sociocultural que os agricultores familiares entrevistados atribuem às coisas da vida, configurando-se como uma verdadeira violência (acesso espoliativo a suas terras).

Aspectos das dimensões teleológica, legal e sociocultural, ante a realidade de Rio Verde, levam os agricultores familiares entrevistados a resistir ao arrendamento rural (especialmente a se tornarem arrendatários para outras categorias sociais). Exemplo disso é o receio quanto ao deslocamento geográfico, pois percebem como suas terras são progressivamente arrendadas nas proximidades das plantações de cana-deaçúcar, sorgo, soja e outros cultivos. Para eles, tais áreas deixam de ser um "pedaço de terra", isto é, deixam de ser espaço de convívio comunitário para formar uma “imensidão contínua das plantações”. Perde-se o lugar de trabalho, de moradia, de cidadania, de vida para suas famílias (CASTRO, 2013).

Os dados das entrevistas em profundidade permitiram identificar uma combinação reflexiva e multidirecional de fatores políticos, sociais, culturais, jurídicos e econômicos, como parte das dimensões e lógicas decorrentes do "habitus", que merecem novas e mais profundas pesquisas. Por esse caminho, o arrendamento rural é uma prática rejeitada pelos agricultores familiares entrevistados, no sudoeste de Goiás. Além da ideia de que o grande empresário agrícola é quem realmente se beneficia (arrendatário de grandes áreas para cultivos comerciais), é percebido (e vivido) como símbolo, instrumento e lugar de exclusão social e marginalização política.

\section{REFERÊNCIAS}

BAIARDI, A. Formas de Agricultura Familiar, à luz dos imperativos de desenvolvimento sustentável e inserção no mercado Internacional. In: XXXVII 
Congresso Brasileiro de Economia e Sociologia Rural, 1999, Foz de Iguaçu. Anais... Brasília: SOBER/1999, v. único, p. 285-297. 1999.

BOURDIEU, P. e WACQUANT, L. An Invitation to Reflexive Sociology. Chicago: University of Chicago Press; Cambridge : Polity. 1992.

BOURDIEU, P. A economia das trocas simbólicas. 6ª ed. SP: Perspectiva. 2009.

Zouk. 2008.

A distinção: crítica social do julgamento. São Paulo: Edusp, Porto Alegre,

BRASIL. Código Civil e legislações ordinárias. Disponíveis em: www. planalto.gov.br/ccivil_03/LEIS. Acesso em: 10.mai. 2017.

CASTELLS, M. A galáxia da internet: reflexões sobre a internet, os negócios e a sociedade. Rio de Janeiro: Jorge Zahar, 2003.

A Era da informação: economia, sociedade e cultura. São Paulo: Paz e Terra. Rio de Janeiro: Jorge Zahar. 2010.

CASTRO, L. F. P.; SAUER S. A Problemática e as Condicionantes dos Arrendamentos Rurais na Agricultura Familiar. In: 50 Congresso da SOBER 2012, Vitória/ES. 2012.

CASTRO, L.F.P. Dimensões e lógicas do arrendamento rural na agricultura familiar. Brasília: PROPAGA/UNB. Dissertação de Mestrado. 2013.

Agricultura Familiar, Habitus e Acesso à Terra. RBSD - Revista Brasileira de Sociologia do Direito, v. 2, p. 91-105. 2015.

Os arrendamentos rurais na agricultura familiar: um estudo de caso em Rio

Verde/GO. Revista em Agronegócio e Meio Ambiente - RAMA. Maringá/PR, v. 10, n. 2. 2017. No prelo.

Agricultura familiar na América Latina: a difusão do conceito e a construção de sujeitos políticos. RBSD - Revista Brasileira de Sociologia do Direito, v. 3, n. 2 , mai./ago. 2016, p. 73-97. 2016.

CATANI, A. M. Espaço social e espaço simbólico: introdução a uma topologia social. Perspectiva. Florianópolis, v. 20, p. 107-120, jul./dez.2002.

DE LA O, A.P; GARNER, E. Defining the "Family Farm". Working paper, FAO. 2012. Disponível em: http://www.fao.org/3/a-i4306e.pdf. Acesso em: 01. maio.17.

FETAEG. Relatório da Federação dos Trabalhadores na Agricultura do Estado de Goiás. Relatório sobre Rio Verde/GO. Rio Verde/GO. 2002.

FERREIRA, A. D. D. Agricultores a agroindústrias: estratégias, adaptações e conflitos. Reforma Agrária - Revista da ABRA, Campinas, v. 25, n. 2/3, mai./dez. 1995, p. 86-113.

FRANÇA, C.G; DEL GROSSI, M.E. e MARQUES, V.P.M.A. O censo agropecuário 2006 e a agricultura familiar no Brasil. MDA. DF: Brasília. 96p. 2009.

IBGE. Censo Agropecuário 2006: Brasil, Grandes Regiões e Unidades da Federação. RJ: Rio de Janeiro. 2007.

INCRA/FAO. Perfil da Agricultura Familiar no Brasil: dossiê estatístico. DF: Brasília. 1996. 
LAMARCHE, H. L'agriculturefamiliale. 1. Une réalité polymorphe. Paris, L'Harmattan; Du mythe à laréalité. Paris, L'Harmattan. 1993.

MALETTA, H. Tendencias y perspectivas de la agricultura familiar en América Latina. Documento de Trabajo $\mathrm{N}^{\circ}$ 1. Proyecto Conocimiento y Cambio en Pobreza Rural y Desarrollo. Santiago do Chile: Rimisp. 2011.

MARQUES, S.; RAMOS, A. Las políticas diferenciadas para la agricultura familiar en el MERCOSUR. Contribución del diálogo político al diseño de las políticas públicas y la institucionalización. S.l.: FIDA. 2012.

NEVES, D. P. Agricultura familiar: questões metodológicas. Revista Reforma Agrária, Campinas, v. 25, nº. 02, jan./abr/1995, p. 21-37. 1995.

PAULILO, M. Produtor e agro-indústria: consensos e dissensos. O caso de Santa Catarina. Florianópolis: UFSC. 1990.

SABOURIN, E., SAMPER, M., e SOTOMAYOR ECHENIQUE. Políticas públicas y agriculturas familiares en América Latina y el Caribe: balance, desafíos y perspectivas. Comisión Económica para América Latina y el Caribe (CEPAL). Colección Documentos de Proyecto. 2014.

SALCEDO, S., e GUZMAN, L. Agricultura familiar en América Latina y el Caribe: recomendaciones de política. Santiago: FAO. 2014.

SAUER, S. A luta pela terra e a reinvenção do rural. XI Congresso Brasileiro de Sociologia. GT-10. 01 a 05 de setembro de 2003. Universidade de Campinas UNICAMP. Campinas/SP. 2003.

Agricultura familiar versus agronegócio: a dinâmica sociopolítica do campo brasileiro. Texto para Discussão, 30, Brasília, Embrapa, 2008.

SAUER, S., LEITE, S.P. Agrarian structure, foreign investment in land, and land prices in Brazil. Journal of Peasants Studies. V. 39, n.34, p. 873-898, 2012.

SCHNEIDER, S. La agricultura familiar en América Latina. In: Abel Cassol. (Org.). La agricultura familiar en América Latina. Roma: FIDA, p. 73-102. 2014.

WANDERLEY, M. Raízes históricas do campesinato brasileiro. In: Tedesco, João Carlos (org), Agricultura familiar: realidade e perspectivas, Passo Fundo, UPF, 1999.

Agricultura familiar e campesinato: rupturas e continuidades. In: WANDERLEY. Maria N. B (org), O mundo rural como espaço de vida: reflexões sobre a propriedade da terra, agricultura familiar e ruralidade. Porto Alegre. UFRGS. 2009a.

O agricultor familiar no Brasil: um ator social da construção do futuro. Revista Agriculturas: experiências em Agroecologia. RJ: Rio de Janeiro. 2009b. 